\title{
Unconventional gas resources in China
}

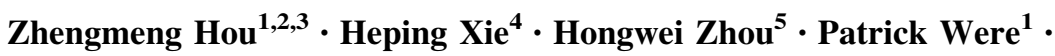 \\ Olaf Kolditz ${ }^{6,7,8}$
}

Published online: 12 April 2015

(C) Springer-Verlag Berlin Heidelberg 2015

Coalbed methane, tight and shale gas are three important unconventional gas resources in China. "According to data from the Ministry of Land and Resources, at the end of 2013, China had 11, 12 and 25 trillion cubic meters, respectively of remaining technically recoverable resources of coalbed methane, tight gas and shale gas which are still in the early stage of development". (Source $\mathrm{CNPC}^{1}$ and ARA International Limited ${ }^{2}$ ).

China is developing its shale gas exploration and exploitation strategies for economic reasons and social aspects (so-called "shale gas revolution"). Huge shale gas reserves provide a reliable source for sustaining China's economic development and contributing to China's "Energiewende". Zhao et al. (2015a) analyze the strategic measures and advantages for a safe and vigorous development of shale gas in China and review the developments of hydraulic fracturing technologies in China. Economic

Olaf Kolditz

olaf.kolditz@ufz.de

1 Energy Research Center of Lower Saxony (EFZN), Clausthal University of Technology, Goslar, Germany

2 Sino-German Energy Research Center, Sichuan University, Chengdu, China

3 Institute of Petroleum Engineering, Clausthal University of Technology, Clausthal-Zellerfeld, Germany

4 Sichuan University, Chengdu, China

5 State Key Laboratory of Coal Resources and Safe Mining, China University of Mining and Technology, Beijing, China

6 Helmholtz Centre for Environmental Research UFZ, Leipzig, Germany

7 Technische Universität Dresden, Dresden, Germany

8 Sino-German Research Centre for Environmental Information Science (RCEIS), Beijing, China exploitation for shale gas is highly dependent on the complexity of the fracture network caused by hydraulic fracturing technology, so it is necessary to accurately assess the effect of the fracture network on gas flow behavior and productivity ( $\mathrm{Li}$ et al. 2015c).

This thematic issue is particularly dedicated to recent researches in unconventional gas resources in China related to the reservoirs indicated in Fig. 1 in order to substitute coal by "clean" gas energy resources as a transitional technology towards renewable energy resources. The thematic issue compiles theoretical, experimental as well as field studies in China. Different reservoir types are under investigation such as tight and shale gas reservoirs as well as coal mines with coalbed methane resources. Fundamental aspects on process understanding in unconventional gas reservoirs as well as the international context of research and technology deployment are discussed in this volume.

Tight gas reservoirs have become an important resource for the world's gas supply. Such reservoirs have very low permeability (usually below $0.1 \mathrm{mD}$ ) and show a strong stress sensitivity to fluid transport properties and a considerable productivity decline during the production process due to decreasing reservoir pressure as well as increasing effective stress. In an experimental study by Albrecht and Reitenbach (2015) several measurement series were performed on plugs from the North-German Rotliegend tight gas reservoirs to determine the effects of changing stress and pore pressure conditions on reservoir

\footnotetext{
${ }^{1}$ CNCP is China's largest oil and gas producer and supplier.

${ }^{2}$ China Natural Gas Map, Project Directories and Reports are products of Global Energy Dialogue research program by the research and publication division of ARA International Limited, and introduce the natural gas industry blueprint by 8.484 critical projects with their status quo, sizes as the value chain relations among each other.
} 
Fig. 1 Overview of shale and tight gas as well as coalbed methane reservoirs in China (Source: World Energy Outlook 2012). The studies presented in this Thematic Issues are dealing with several reservoirs: the Ordos Basin (Liu et al. 2015b), Sichuan Basin (Lu et al. 2015), Songliao Basin (Liu et al. 2015c)

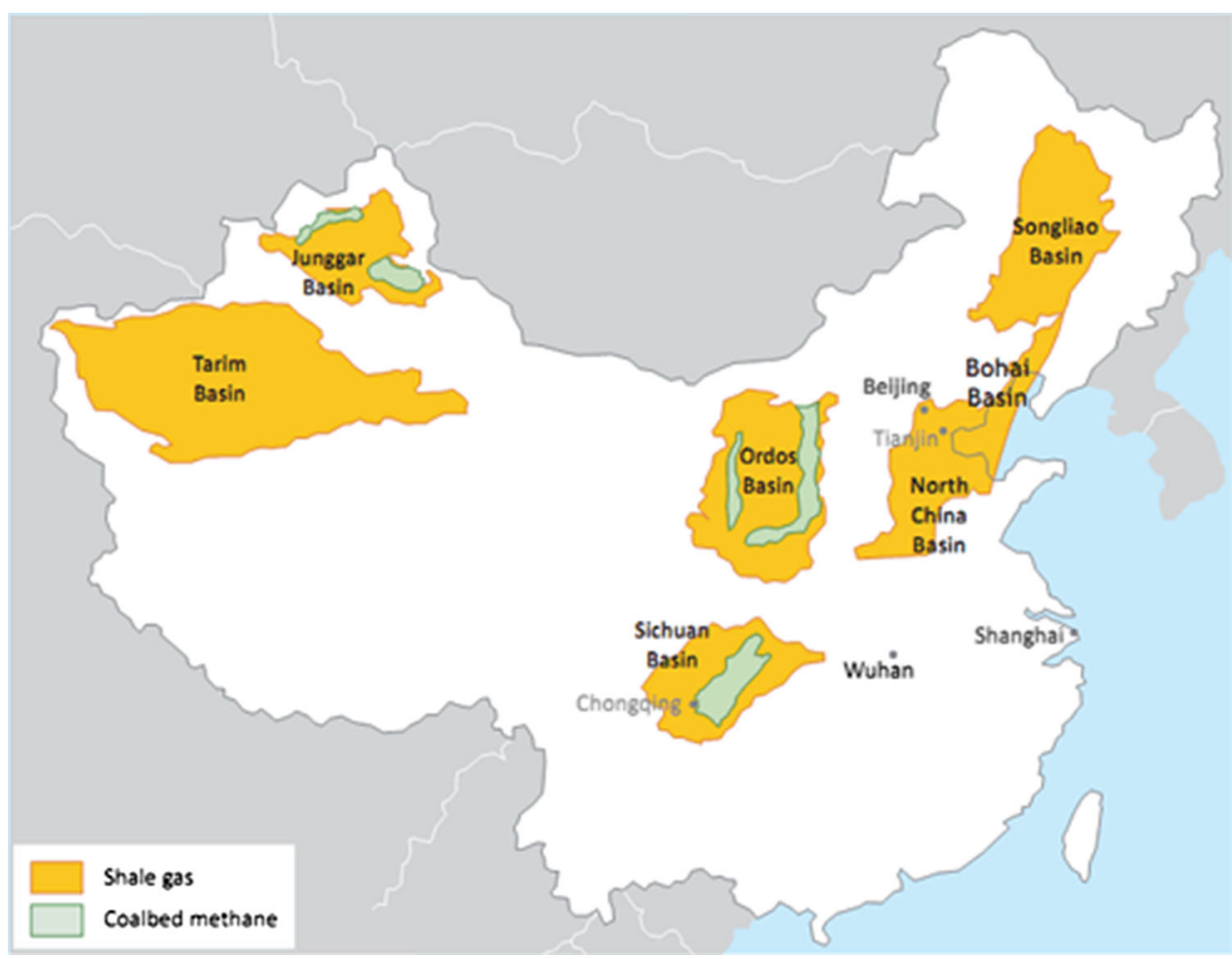

rocks during gas production. Zhou et al. (2015) are dealing with numerical modeling and investigation of fracture propagation with arbitrary orientation through fluid injection in tight gas reservoirs in particular to investigate the fracture orientation problem (propagating not necessarily perpendicular to the minimum horizontal stress). They are combining different numerical methods namely the extended finite element method (XFEM) and the finite volume method (FVM). Prediction of aqueous phase trapping in tight reservoirs is of great importance, since well productivity can be improved through proper estimation and consequent attempts to reduce formation damage. Sun et al. (2015) developed a model for predicting aqueous phase trapping damage in tight reservoirs using quantum neural networks. Feng et al. (2015) conducted numerical and semi-analytical investigations to better understand the hydraulic fracturing operation in tight gas reservoirs. They used different models (numerical, full 3D model and semianalytical, modified model based on the conventional pseudo-3D model) to simulate fracturing operations including fracture propagation, proppant transport and settling. Drilling horizontal wells with multi-stage fracturing is the key technique to maximize stimulated reservoir volume and achieve efficient gas production from tight gas reservoirs. The spacing between wellbore perforations has a significant impact on well production. Lu et al. (2015) analyzed and verified this technology with data from a tight sandstone reservoir in Sichuan Basin of China.
High brittleness is a prerequisite for permeability enhancement in shale gas reservoirs. Guo et al. (2015b) present a new method for shale brittleness evaluation starting from the mechanism of rock failure to considering the effect of rock mechanical properties on brittleness. Zhao et al. (2015b) study the influence of interfacial slip on fracture height propagation and investigate measures to prevent fracture height overgrowth during shale gas fracturing simulations. They found that the influence of interfacial slip on fracture height propagation must be taken into consideration in fracturing simulations for shale gas reservoirs. Liu et al. (2015c) report on the Xushen gas field in the Songliao Basin (Northeast China). Gas fields were developed in Songliao Basin since 2004 in order to balance gas producing areas especially by "using a gas to supply oil output" strategy in Daqing oilfield. Gas fields in Northeast China are challenged by the very cold climate, poor reservoir property and high amounts of $\mathrm{CO}_{2}$ in natural gas as well as possible formation of natural gas hydrates. The study by Liu et al. (2015b) indicates that the surface engineering construction would take up more than $30 \%$ of the total investment in the gas field development. $\mathrm{Li}$ et al. (2015a) numerically investigated gas flow in fractured shale reservoirs. Processes at different scales need to be addressed including the gas desorption from shale matrix, Knudsen flow in nano-scale pores, Darcy flow in porous media, etc. The extended finite element method (XFEM) has been integrated with the dual permeability method 
(DPM) to investigate the multi-scale problem. Multiple types of pores exist in shale gas reservoirs, including organic pores at nano scale, non-organic pores, natural and hydraulic fractures. Gas flow in different types of pores is controlled by different mechanisms, and Darcy's law is not suited to describe all relevant processes adequately. Guo et al. (2015a) present a "quadruple-porosity" model and corresponding analytical solutions to describe the different permeable media and simulate transient production behavior of multiple-fractured horizontal wells in shale gas reservoirs.

Liu et al. (2015a) investigate mechanical properties and behavior of coal and rocks under both static and dynamic loading rates considering the bedding directivity which is important in the coal mining practices. Xie et al. (2015) provide theoretical and experimental proofs of mining-enhanced permeability for simultaneous exploitation of coal and gas. Simultaneous production of coal and methane is a promising solution for making reasonable use of energy resources and preventing gas disasters. Xue et al. (2015) suggested a combined method for evaluation and prediction of permeability enhancement in coal seams induced by strata stress release. Lin and Shen (2015) developed effective methods to improve the coal seam permeability using multilevel slotting by water jets and application in coal mine gas extraction. They used particle flow methods to numerically simulate fracture, stress, and porosity evolutions of the multilevel slotting coal. Wang et al. (2015a) studied the mechanical characteristics and permeability properties of sandstone and limestone from a coal mine, in particular the mechanical characteristics and permeability, before and after the rock failure under hydro-mechanical coupling conditions. Zhang et al. (2015b) studied the relationships among stress, effective porosity and permeability of coal considering the distribution of natural fractures by theoretical and experimental analyses. A series of effective porosity and permeability measurements have been conducted under different overburden stresses to obtain a profound understanding of the interrelationships among stress, effective porosity and permeability of coal. Accurate knowledge of thermos-physical properties (such as specific heat capacity, thermal conductivity, and thermal diffusivity) is important to coal in situ gasification with environmental treatments. Tang et al. (2015) experimentally investigated thermos-physical properties for different rocks of coal measure strata at a wide range of temperatures. Related studies to coal mines in China are provided by $\mathrm{Zhu}$ et al. (2014).

Several studies are dealing with fundamental aspects on process understanding in unconventional gas reservoirs (e.g. hydraulic fracturing). Gou et al. (2015) conduct numerical study on hydraulic fracturing in different types of georeservoirs including tight gas, oil, and geothermal reservoirs. They consider hydro-mechanical coupled leakoff effects. Li et al. (2015c) provided a fundamental study on progressive failure constitutive model for softening behavior of rocks. A new statistical damage constitutive model is proposed to describe the progressive failure of rocks under triaxial stress conditions. The model is based on continuous damage mechanics and maximum entropy theory. Li et al. (2015b) numerically investigated heat transport processes in subsurface reservoirs with horizontal wells and multiple fractures. Several studies are dealing with simulation of hydraulic fracturing processes (Lange et al. 2013; Kissinger et al. 2013; Zhao et al. 2015a, b; Marina et al. 2014; Eshiet et al. 2013). Benchmarking e.g. by comparing different conceptual models, is an approved methodology for improving process understanding under complex conditions, i.e. coupled processes or nonlinearities (Kolditz et al. 2012; Hou et al. 2012; Wang and Chen 2013). Numerical modeling of hydro-mechanical processes including non-isothermal processes in georeservoirs is extremely computational time consuming and requires efficient computational algorithms such as massive parallelization (Wang et al. 2015b; Huang et al. 2014; Watanabe et al. 2012).

Unconventional gas resources including other related aspects of geoenergy research (e.g. geothermal resources, CCS and energy storage in the subsurface) are of great significance in many areas of the world building an international context for this Thematic Issue focussed on unconventional gas resources in China. Enhanced gas recovery is one technology to improve the productivity of depleting reservoirs. In Germany, the CLEAN and MoPa projects were dealt with different scientific aspects of conventional and unconventional gas resources in the context of CO2 storage (Kuehn et al. 2012a, b; Huebner et al. 2013; Singh et al. 2011; Bauer et al. 2012). Hammes et al. (2013) assessed the unconventional reservoir potential of the upper Permian Zechstein Group in Northern Germany by stratigraphic and sedimentological evaluation of carbonates and organic-rich mudrocks. Gordalla et al. (2013) investigated the toxicological threat for groundwater and drinking-water by hydraulics fracturing. Ecotoxicological and waste water assessments of fracturing fluids were conducted by Riedl et al. (2013) and Olsson et al. (2013). Uth (2014) investigated technical risks and best available technology of hydraulic fracturing in unconventional natural gas resources. Advanced numerical simulation tools for different aspects in hydraulic fracturing such as carbon capture and storage (CCS) have been developed e.g. by Eshiet and Sheng (2014a, b). Hydraulic fracturing is also a research issue in soil science (Galeandro et al. 2014).

Hydraulic fracturing is also used as a technology for enhancing groundwater abstraction from chalk aquifers in 
Africa (Qian et al. 2014) and Brazil (Fontenele et al. 2014), in karst hydrology (Schrader et al. 2014) or even bioclogging of porous media (Zhong and $\mathrm{Wu} 2013$ ).

A more comprehensive utilization of geo-reservoirs as a potential geoenergy resource was discussed in other related Thematic Issues in EES recently (Scheck-Wenderoth et al. 2013; Nagel et al. 2013), in particular the development of geothermal energy resources (Huenges et al. 2013). New technologies for data mining, simulation and data visualization as continuous workflows became more important to terrestrial environmental research (Kolditz et al. 2012; Bilke et al. 2014).

Acknowledgments Both Chinese and German sides gratefully appreciate the funding of international cooperative projects by MOST (Ministry of Science and Technology of China, Grant Number: 2012DFA60760), NSFC (National Natural Science Foundation of China, Grant Number: 51120145001), NSFC and DFG (Deutsche Forschungsgemeinschaft, Grant Number: GZ573). The Chinese side gratefully acknowledges the supports by the 973 Program (Grant Number: 2011CB201200), NSFC (Grant Number: 11172318, $51134018,51374147)$, the specialized research fund for the doctoral program of higher education (Grant Number: 20130023110017). We are grateful to the Helmholtz Association for funding the GermanChinese Research Centre for Environmental Information SciencesRCEIS (Grant HIRN-0002). The authors thank Mr. Zhang (CNPC) for providing information concerning the unconventional gas reserves in China.

\section{References}

Albrecht D, Reitenbach V (2015) Investigations on fluid transport properties in the North-German Rotliegend tight gas sandstones and applications. Environ Earth Sci. doi:10.1007/s12665-0154322-x

Bauer S, Class H, Ebert M et al (2012) Modeling, parameterization and evaluation of monitoring methods for $\mathrm{CO} 2$ storage in deep saline formations: the $\mathrm{CO} 2 \mathrm{MoPa}$ project. Environ Earth Sci 67(2):351-367

Bilke L, Fischer T, Helbig C et al (2014) TESSIN VISLab-laboratory for scientific visualization. Environ Earth Sci 72(10):3881-3899

Eshiet K, Sheng Y (2014a) Investigation of geomechanical responses of reservoirs induced by carbon dioxide storage. Environ Earth Sci 71(9):3999-4020

Eshiet K, Sheng Y (2014b) Carbon dioxide injection and associated hydraulic fracturing of reservoir formations. Environ Earth Sci 72(4):1011-1024

Eshiet KI, Sheng Y, Ye J (2013) Microscopic modelling of the hydraulic fracturing process. Environ Earth Sci 68(4):1169-1186

Feng W, Hou Z, Zhou L, Li M, Were P (2015) Semi-analytical and numerical investigation of hydraulic fracturing and geological barrier integrity based on a case study. Environ Earth Sci. doi:10. 1007/s12665-015-4306-x

Fontenele SdB, Ribeiro Mendoca LA, de Araujo JC et al (2014) Relationship between hydrogeological parameters for datascarce regions: the case of the Araripe sedimentary basin, Brazil. Environ Earth Sci 71(2):885-894

Galeandro A, Doglioni A, Simeone V et al (2014) Analysis of infiltration processes into fractured and swelling soils as triggering factors of landslides. Environ Earth Sci 71(6): 2911-2923
Gordalla BC, Ewers U, Frimmel FH (2013) Hydraulic fracturing: a toxicological threat for groundwater and drinking-water? Environ Earth Sci 70(8):3875-3893

Gou Y, Zhou L, Zhao X, Hou Z, Were P (2015) Numerical study on hydraulic fracturing in different types of georeservoirs with consideration of H2M-coupled leak-off effects. Environ Earth Sci. doi:10.1007/s12665-015-4112-5

Guo J, Zhang L, Zhu Q (2015a) A quadruple-porosity model for transient production analysis of multiple-fractured horizontal wells in shale gas reservoirs. Environ Earth Sci. doi:10.1007/ s12665-015-4368-9

Guo JC, Zhao ZH, He SG, Liang H, Liu YX (2015b) A new method for shale brittleness evaluation. Environ Earth Sci. doi:10.1007/ s12665-015-4268-Z

Hammes U, Krause M, Mutti M (2013) Unconventional reservoir potential of the upper Permian Zechstein Group: a slope to basin sequence stratigraphic and sedimentological evaluation of carbonates and organic-rich mudrocks, Northern Germany. Environ Earth Sci 70(8):3797-3816

Hou Z, Gou Y, Taron J et al (2012) Thermo-hydro-mechanical modeling of carbon dioxide injection for enhanced gas-recovery (CO2-EGR): a benchmarking study for code comparison. Environ Earth Sci 67(2):549-561

Huang Y, Zhou Z, Wang J et al (2014) Simulation of groundwater flow in fractured rocks using a coupled model based on the method of domain decomposition. Environ Earth Sci 72(8): $2765-2777$

Huebner A, Horsfield B, Kapp I (2013) Fact-based communication: the Shale Gas Information Platform SHIP. Environ Earth Sci 70(8):3921-3925

Huenges E, Kohl T, Kolditz O et al (2013) Geothermal energy systems: research perspective for domestic energy provision. Environ Earth Sci 70(8):3927-3933

Kissinger A, Helmig R, Ebigbo A et al (2013) Hydraulic fracturing in unconventional gas reservoirs: risks in the geological system, part 2. Environ Earth Sci 70(8):3855-3873

Kolditz O, Bauer S, Beyer C et al (2012) A systematic benchmarking approach for geologic $\mathrm{CO} 2$ injection and storage. Environ Earth Sci 67(2):613-632

Kuehn M, Tesmer M, Pilz P et al (2012a) CLEAN: project overview on $\mathrm{CO} 2$ large-scale enhanced gas recovery in the Altmark natural gas field (Germany). Environ Earth Sci 67(2):311-321

Kuehn M, Goerke UJ, Birkholzer JT et al (2012b) The CLEAN project in the context of $\mathrm{CO} 2$ storage and enhanced gas recovery. Environ Earth Sci 67(2):307-310

Lange T, Sauter M, Heitfeld M et al (2013) Hydraulic fracturing in unconventional gas reservoirs: risks in the geological system part 1. Environ Earth Sci 70(8):3839-3853

Li CB, Xie LZ, Ren R, Wang J (2015a) Progressive failure constitutive model for softening behavior of rocks based on maximum entropy theory. Environ Earth Sci. doi:10.1007/ s12665-015-4228-7

Li M, Gou Y, Hou Z, Were P (2015b) Investigation of a new HDR system with horizontal wells and multiple fractures using the coupled wellbore-reservoir simulator TOUGH2MP-WELL/ EOS3. Environ Earth Sci. doi:10.1007/s12665-015-4242-9

Li Y, Jiang Y, Zhao J, Liu C, Zhang L (2015c) Extended finite element method for analysis of multi-scale flow in fractured shale gas reservoirs. Environ Earth Sci. doi:10.1007/s12665-0154367-x

Lin B, Shen C (2015) Coal permeability-improving mechanism of multilevel slotting by water jet and application in coal mine gas extraction. Environ Earth Sci. doi:10.1007/s12665-015-4154-8

Liu X, Dai F, Zhang R, Liu J (2015a) Static and dynamic uniaxial compression tests on coal rock considering the bedding directivity. Environ Earth Sci. doi:10.1007/s12665-015-4106-3 
Liu Y, Li J, Wang Z, Wang S, Dong Y (2015b) The role of surface and subsurface integration in the development of a high pressure and low production gas field. Environ Earth Sci. doi:10.1007/ s12665-015-4341-7

Liu Y, Wang F, Tang H, Liang S (2015c) Well type and pattern optimization method based on fine numerical simulation in coalbed methane reservoir. Environ Earth Sci. doi:10.1007/s12665$015-4375-x$

Lu C, Guo JC, Liu YX, Yin J, Deng Y, Lu QL, Zhao X (2015) Perforation spacing optimization for multi-stage hydraulic fracturing in Xujiahe formation - a tight sandstone formation in Sichuan Basin of China. Environ Earth Sci. doi:10.1007/ s12665-015-4366-y

Marina S, Imo-Imo EK, Derek I, Mohamed P, Yong S (2014) Modelling of hydraulic fracturing process by coupled discrete element and fluid dynamic methods. Environ Earth Sci 72(9):3383-3399

Nagel T, Shao H, Singh AK et al (2013) Non-equilibrium thermochemical heat storage in porous media: part 1-conceptual model. Energy 60:254-270

Olsson O, Weichgrebe D, Rosenwinkel KH (2013) Hydraulic fracturing wastewater in Germany: composition, treatment, concerns. Environ Earth Sci 70(8):3895-3906

Qian J, Zhou X, Zhan H et al (2014) Numerical simulation and evaluation of groundwater resources in a fractured chalk aquifer: a case study in Zinder well field, Niger. Environ Earth Sci 72(8):3053-3065

Riedl J, Rotter S, Faetsch S et al (2013) Proposal for applying a component-based mixture approach for ecotoxicological assessment of fracturing fluids. Environ Earth Sci 70(8):3907-3920

Scheck-Wenderoth M, Schmeisser D, Mutti M et al (2013) Geoenergy: new concepts for utilization of geo-reservoirs as potential energy sources. Environ Earth Sci 70(8):3427-3431

Schrader A, Winde F, Erasmus E (2014) Using impacts of deep-level mining to research karst hydrology — a Darcy-based approach to predict the future of dried-up dolomitic springs in the Far West Rand goldfield (South Africa). Part 2: predicting inter-compartmental flow and final groundwater tables. Environ Earth Sci 72(7):2583-2595

Singh AK, Goerke UJ, Kolditz O (2011) Numerical simulation of non-isothermal compositional gas flow: application to carbon dioxide injection into gas reservoirs. Energy 36(5):3446-3458

Sun Y, Zhao J, Bai M (2015) Predicting aqueous phase trapping damage in tight reservoirs using quantum neural networks. Environ Earth Sci. doi:10.1007/s12665-015-4247-4

Tang F, Wang L, Lu Y, Yang X (2015) Thermophysical properties of coal measure strata under high temperature. Environ Earth Sci. doi:10.1007/s12665-015-4364-0

Uth HJ (2014) Technical risks and best available technology (BAT) of hydraulic fracturing in unconventional natural gas resources. Environ Earth Sci 72(6):2163-2171
Wang H, Chen J (2013) A study on the permeability and flow behavior of surfactant foam in unconsolidated media. Environ Earth Sci 68(2):567-576

Wang L, Liu JF, Pei JL, Xu HN, Bian Y (2015a) Mechanical and permeability characteristics of rock under hydro-mechanical coupling conditions. Environ Earth Sci. doi:10.1007/s12665015-4190-4

Wang W, Fischer T, Zehner B et al (2015b) A parallel finite element method for two-phase flow processes in porous media: OpenGeoSys with PETSc. Environ Earth Sci 73(5):2269-2285

Watanabe N, Wang W, Taron J et al (2012) Lower-dimensional interface elements using local enrichments and application for a coupled hydromechanical problem in fractured rock. Int J Numer Meth Eng 90(8):1010-1034. doi:10.1002/nme.3353

Xie H, Xie J, Gao M, Zhang R, Zhou H, Gao F, Zhang Z (2015) Theoretical and experimental validation of mining-enhanced permeability for simultaneous exploitation of coal and gas. Environ Earth Sci. doi:10.1007/s12665-015-4113-4

Xue DJ, Zhou HW, Chen CF, Jiang DY (2015) A combined method for evaluation and prediction on permeability in coal seams during enhanced methane recovery by pressure-relieved method. Environ Earth Sci. doi:10.1007/s12665-015-4378-7

Zhang R, Ai T, Zhou HW, Ju Y, Zhang ZT (2015a) Fractal and volume characteristics of 3D mining-induced fractures under typical mining layouts. Environ Earth Sci. doi:10.1007/s12665015-4376-9

Zhang Z, Zhang R, Xie H, Gao M (2015b) The relationships among stress, effective porosity and permeability of coal considering the distribution of natural fractures: theoretical and experimental analyses. Environ Earth Sci. doi:10.1007/s12665-015-4280-3

Zhao J, Liu C, Yang H, Li Y (2015a) Strategic questions about China's shale gas development. Environ Earth Sci. doi:10.1007/ s12665-015-4092-5

Zhao J, Peng Y, Li Y, Xiao W (2015b) Analytical model for simulating and analyzing the influence of interfacial slip on fracture height propagation in shale gas layers. Environ Earth Sci. doi:10.1007/s12665-015-4360-4

Zhong X, Wu Y (2013) Bioclogging in porous media under continuous-flow condition. Environ Earth Sci 68(8):2417-2425

Zhou L, Gou Y, Hou Z, Were P (2015) Numerical modeling and investigation of fracture propagation with arbitrary orientation through fluid injection in tight gas reservoirs with combined XFEM and FVM. Environ Earth Sci. doi:10.1007/s12665-0154051-1

Zhu B, Wu Q, Yang J et al (2014) Study of pore pressure change during mining and its application on water inrush prevention: a numerical simulation case in Zhaogezhuang coalmine, China. Environ Earth Sci 71(5):2115-2132 